Funding: See page 271

Peer review: This article has been subject to a double blind peer review process

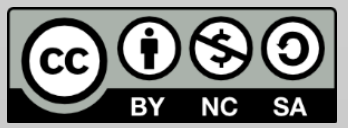

C Copyright: The Authors. This article is issued under the terms of the Creative Commons Attribution NonCommercial Share Alike License, which permits use and redistribution of the work provided that the original author and source are credited, the work is not used for commercial purposes and that any derivative works are made available under the same license terms.

\section{Exploring the Interconnections between Culture and Behaviour: an Interdisciplinary Conference at the University of Warwick}

\author{
Carolin Debray*, Thomas Greenaway, Kyoungmi Kim
}

Centre of Applied Linguistics, University of Warwick

*Correspondence: C.Debray@warwick.ac.uk

\begin{abstract}
In this article we reflect on the 'Interconnections between Culture and Behaviour: Interdisciplinary Perspectives' conference. The event brought together renowned scholars from the fields of psychology and sociology to applied linguistics, who presented the conceptualisations made and methodological approaches taken to explore culture and behaviour in their respective disciplines. In table discussions the participants debated the commonalities and differences between their respective disciplines and reflected on their own approaches. In a final plenum discussion speakers and participants questioned the compatibility of approaches in order to explore opportunities for interdisciplinary research. No discipline denied that links between culture and behaviour exist, but that other constructs are needed to explore them further, such as norms. The contexts in which behaviours are observed were also highlighted as crucial by all speakers, although they operationalised it quite differently. All sides acknowledged the value of multi- or interdisciplinary approaches when researching the links between culture and behaviour. However, philosophical differences affecting practical issues, such as data collection methods and analytical tools, were also identified as impacting compatibility. Following the discussions at the event, speakers and organisers decided to further explore these ideas in a special issue, which is currently in preparation.
\end{abstract}

Keywords: Interconnections between culture and behaviour, interdisciplinary approaches, norms, interactions, context, research collaborations

\section{Background and Aim of the Event}

Our motivation for the event came out of our own struggles with conceptualising culture and behaviour and their possible interconnections, which, though not the main focus of our own research, 
seemed to be a controversial issue which we, the authors, repeatedly had to engage with. It seemed to be a topic relevant to several disciplines and to many different types of work, which encouraged us to explore it further. Having discussed it repeatedly in the Working and Communicating across Cultures research group meetings at Warwick's Centre for Applied Linguistics, we came to realise that despite spanning several disciplines and fields, the interconnections between culture and behaviour remained very much under-theorised and did not provide any satisfactory answers to our own research challenges. Questions such as: 'To what extent does culture influence individual behaviour?'; 'To what extent is culture to be seen as a product of behaviour?'; 'How much agency do individuals have to influence their own decisions and behaviour?'; 'Individuals are always surrounded by multiple layers of culture such as national culture, organisational culture or regional and local cultures, how do individuals interact with these different layers in regards to their behaviour?' were at the core of these debates. These seemed to be particularly important questions considering the widely adopted macro-approaches taken in business literature, in which similar values and behaviours are ascribed to large groups of people, which seemed, however, unsatisfactory to our minds. While research in several disciplines addresses and incorporates notions on culture and behaviour, they seem to be defined quite differently. However more, it seems that few exchanges seem to have occurred thus far, despite the great opportunities for learning and for gaining new perspectives.

The aim of the conference was therefore firstly to gain insights into how different disciplines are approaching and conceptualising the interconnections between culture and behaviour. This was meant both to enrich each participant's individual understanding of the concept and to provide new insights to the different disciplines. For this reason a large amount of time was reserved for discussions that allowed participants to discuss their own work in the light of some of the newly introduced approaches and to find the concept best suited to them. At the same time we wanted to explore the common ground between the approaches as well as the extent to which they differed, with the goal of exploring new multi- or interdisciplinary approaches, sparking interesting discussions and new collaborations. We will consider these differences and how culture and behaviour are defined by different disciplines in the discussion of the event below.

\section{The Event Format}

Four presentations were given at the conference in which speakers introduced their own approaches to the overarching topic, with one 
presentation being held by two speakers. To allow for comparisons between their talks and to spark useful discussions, the speakers were sent questions in advance, which they were asked to address in their talks.

Main questions

- How do you think one can conceptualise and/or research the links between culture and behaviour?

- How can we conceptually and methodologically capture the links between culture and behaviour on multiple levels of analysis: Societies, organisations, teams, individuals, etc.?

Supplementary questions

- How are the concepts of 'culture' and 'behaviour' understood in your discipline?

- What role do culture and behaviour play in your own research/the research in your field?

Each presentation lasted for 30 minutes and was followed by a 30minute discussion. The discussions were held around tables in small groups, which were changed after each talk. We found, however, that the discussions did not cease during coffee and lunch breaks and extended well beyond the original event.

\section{Speakers and Stances}

The invited speakers were all established names in their field and were chosen based on their previous engagement with the topic. The following section will give a brief overview of the content of their talks.

\section{Klaus Schneider}

Starting with a quote by Edward Sapir '... language does not exist apart from culture, that is, from the socially inherited assemblage of practices and beliefs that determines the textures of our lives' (1921: 207), Professor Klaus Schneider approached the interconnections between culture and behaviour from the standpoint of Variational Pragmatics. This field investigates how language use differs both across and within languages, with differences usually being assumed to be due to differences in local or contextual norms or underlying values. Professor Schneider exemplified these assumptions by looking at cultural variations in responses to 'thanks' and 'small talk' in different English speaking 
countries. Schneider described the differences in behavioural patterns across countries as 'reproductions of discursive formats that have become institutionalised as expectable and appropriate behaviour', which he connected to cultural values. Methodologically he suggested a two-step procedure for connecting culture and behaviour that includes an experimental stage followed by triangulation with naturally occurring data. While this approach is not unheard of in other fields it does not represent the standard approach in either Pragmatics or Applied Linguistics, but Professor Schneider highlighted its importance in validating research findings.

Bio: Professor Klaus Schneider

- Chair in Applied English Linguistics at the University of Bonn.

- President of the German Association for the Study of English (Deutscher Anglistenverband).

- Main Research Interest: (Cross Cultural) Pragmatics.

\section{Ron Fischer}

Ron Fischer began his talk with a critical look at research in his own field of cross-cultural psychology. This involved defining culture 'as a shared meaning system', comparing differences in researching individuals and national groups, and the lack of strong theory in cross-cultural research. He then went on to compare cross-cultural research outcomes to Dante's seven circles of hell, and the academic sins associated with it. This indicated a departure from the aggregations of values to explain national culture that cross-cultural psychology is renowned for (e.g. Hampden-

Turner \& Trompenaars, 1997; Hofstede, 2001; House et al. 2004). After addressing the pre-event questions given to him, Fischer deducted that in the future we need:

- More behaviour research with observations in context.

- To unpack 'culture' further by bringing research from biology, history, ecology, etc.

Fischer then showcased how researchers are now challenging the methodology of previous findings on culture-dependent behaviour by experimenting with more contextual variables. He concluded that we need stronger experiments to test for the links between culture and behaviour. Following this conclusion, he suggested a methodology for carrying out such experiments (see Fischer, 2009) whereby research should begin with looking at 'culture as a shared meaning system.' 


\section{Bio: Professor Ron Fischer}

- Based at the University of Wellington, New Zealand.

- Associate editor of the Journal of Cross Cultural Psychology.

- Main Research Interests: cross-cultural psychology and crosscultural research methods.

\section{Adrian Holliday}

Questioning how we can conceptualise culture without falling into the trap of being too deterministic about culture, Adrian Holliday began his talk detailing his constructivist stance on culture. In relation to the conference theme, he presented his framework, 'grammar of culture' and focussed on 'cultural processes' that are considered to be universal and found in our everyday life. To Holliday, cultural processes involve cultural knowledge and skills through which people engage and negotiate their positions in their everyday life. In particular, he drew on his notion of 'small cultures' as a cultural environment in which small social groupings or activities can be found. Thus for him, cultural formation is an on-going group process through which people consistently create rules for how to behave within changing circumstances, which in turn helps them understand and engage with cultural behaviour. By exemplifying his recent work on the intercultural perceptions and behaviour of 'home' and 'international' students, he demonstrated how perceptions and behaviours of individuals emerged and thus have to be seen as non-deterministic (Holliday, 2016). He also elaborated on how culture emerges and changes with individuals creating small communities forming their own norms. In order to explore the negotiation of culture and behaviours over time Holliday suggested further ethnographic research. This could help to reveal how people expand their behavioural repertoire and construct culture within the particular social structure.

\section{Bio: Adrian Holliday}

- Professor of Applied Linguistics at Canterbury Christ Church University.

- Main Research Interests: Intercultural Communication and Ideology, Discourses of Culture. 


\section{Bethan Benwell \& Jo Angouri}

Bethan Benwell and Jo Angouri, both sociolinguists, gave the final presentation of the day. They began by defining how culture and behaviour are conceptualised in their fields. Culture for them is related to problematised constructs such as context, norms and historicity, while behaviour is less controversial, and linguistic practices are treated as 'behaviour'. Benwell then outlined the approaches within Conversation Analysis (CA), where culture is, if at all, discussed as an emergent phenomenon. In CA, conclusions about culture can only be warranted if evident within the interaction. Angouri then introduced Interactional Sociolinguistics, which situates interactions in their socio-political context, by drawing from macro discourses to explain interactions. Angouri gave evidence from her own research looking at gendered discourse when explaining workplace conversations, which she triangulated with interview data. They concluded that sociolinguistics could help explain culture and behaviour in micro interactions, but that there were limitations to the field: interpretations drawn from the interactions are dependent on the analyst and interactional sociolinguistics does not fully theorise on concepts brought in from other disciplines. Therefore, the 'what' and 'how' of an interactions can be explained, but not the 'why.'

\section{Bio: Dr Bethan Benwell}

- Senior lecturer in English Language and Linguistics at the University of Stirling.

- Co-author of the book (with Elizabeth Stokoe) Discourse and Identity (2006).

- Research Interests: discourse analysis, NHS health care interactions.

Bio: Dr Jo Angouri

- Associate professor at the University of Warwick is a sociolinguist

- Research Interests: Relationship between language, culture and identity, representations of the financial crisis in every discourse. 


\section{Critical Review of how the Interconnections of Culture and Behaviour were explored at the Conference}

In the following section we will reflect on and review how the different speeches are linked to each other, and where stances differed.

\section{Levels of Cultural Analysis and Research Focus}

Both Fischer and Schneider compare culture at macro and micro levels. While Schneider looks at patterns of language choices in speech communities across cultures, Fischer investigates behavioural phenomena across cultures (e.g. how bribery and nepotism is perceived in different cultural settings). In contrast Holliday, Benwell and Angouri focused more on the individual and small-group level, with Benwell and Angouri researching interactions and Holliday investigating narratives of sense-making.

Table 1: The Speakers' Levels of Cultural Analysis and Research Focus

\begin{tabular}{|l|l|l|}
\hline Speaker & Level of Analysis & Focus \\
\hline Ron Fischer & $\begin{array}{l}\text { Comparison of } \\
\text { culture at micro- and } \\
\text { macro-level }\end{array}$ & $\begin{array}{l}\text { Behavioural } \\
\text { phenomena across } \\
\text { cultures }\end{array}$ \\
\hline Klaus Schneider & $\begin{array}{l}\text { Comparison of } \\
\text { culture at micro- and } \\
\text { macro-level }\end{array}$ & $\begin{array}{l}\text { Patterns of language } \\
\text { choices in speech } \\
\text { communities across } \\
\text { cultures }\end{array}$ \\
\hline Adrian Holliday & $\begin{array}{l}\text { Individual \& small } \\
\text { group level }\end{array}$ & $\begin{array}{l}\text { Self-representations } \\
\text { Bethan Benwell } \\
\text { \& Jo Angouri }\end{array}$ \\
$\begin{array}{l}\text { Individual \& small } \\
\text { group level }\end{array}$ & $\begin{array}{l}\text { Small scale } \\
\text { interactions in } \\
\text { relation to larger } \\
\text { discourses }\end{array}$ \\
\hline
\end{tabular}

Importance of Context in Culture and Behaviour

All speakers agreed that context is of primary concern when looking to explain the interconnections between culture and behaviour; however, the way they consider context in their own research differs. Both Schneider and Fischer looked at instances of similar behaviour across 
cultures but highlighted local, contextual variations. Schneider emphasised that generalisable findings can never be made by looking at just one localised context; therefore, we need to look at behaviour across contexts while being aware of their differences. In contrast, Holliday took a more critical stance towards macro approaches, suggesting that this would lead to 'unrecognised cultural realities'. Angouri and Benwell were closer to Holiday's stance, emphasising that behaviour cannot be understood without looking at its immediate context and without considering the interactional processes that led to the behaviour observed. However, they also stated that micro interactions can be better understood by considering larger societal discourses which impact on and are emergent in interactions. This difference is important to be aware of when contemplating suitable interdisciplinary approaches. The participants discussed these differences more as an opportunity rather than a drawback as they can lead to a more comprehensive understanding of a particular phenomenon.

\section{Conceptualisations of Culture and Behaviour}

In order to explore the links between culture and behaviour speakers firstly defined both notions to then see how they were interconnected. Schneider focused on linguistic behaviour. Following Sapir (1921), he stated that language does not exist apart from culture and conceptualised culture as socially inherited practices and beliefs. Considering the assumption that language cannot be understood to exist apart from culture, language use and interactions are therefore culturally influenced, thus Schneider established a fairly direct link between (linguistic) behaviour and culture. In contrast Holliday positioned himself against presuming links between culture and behaviour, saying, 'the relationship between culture and behaviour is some sort of negotiated, creative engagement.' He warned the participants further that behaviour is not a neutral concept, because it is often associated with values and standards. When researching, Holliday advised that we put aside common perceptions of behaviour, and instead take a close look at behaviour's emergent aspect in cultural processes. Similarly, Angouri and Benwell see culture as a phenomenon that emerges; however, they specifically focus on interactions. For them interactions are influenced by shared knowledge of cultural norms. Those norms emerge and become evident in linguistic behaviours.

In contrast, Fischer's conceptualisations of culture and behaviour differed from the other speakers and he problematised the link between them differently. For him culture is a shared meaning system (following Geertz, 1973), and behaviours are observed in context (although many in his field 
have linked behaviour to values, which is contested). Fischer's conceptualisation of behaviour was broader and included practices beyond linguistic behaviour. This was in contrast with Benwell, Schneider and Angouri, who all conceptualised behaviour with reference to language in their own research.

Following from this, some methodological implications also need to be considered. Schneider and Fischer agreed that a two-step approach consisting of combining experimental and real world data would yield the best insights into culture and behaviour. As experimental researchers (i.e. researchers who collect data in controlled contexts) they looked to ethnographic methods (amongst others) to help validate their own findings. For the other speakers, rather than looking at experiments to supplement their understanding of real world data, they looked to critical perspectives and ideology. This contrast in methodological approaches was not discussed in depth; yet from our point of view further discussions are needed in order to gain a better understanding of potential interdisciplinary approaches.

How one defines culture and behaviour seems to set the terms of the research and influences the methodology and the researcher's interpretation of data. If defined too distinctly, joint approaches might become impossible as ontological questions are at its core.

For successful collaboration, we need to appreciate the limitations of individual approaches, but also recognise where the findings from one paradigm can inform research from another. While at the moment it seems that there is still a long way to go in this regard, all speakers seemed to agree that shared knowledge of, or assumptions about cultural norms, influence behaviour. We think that this common ground could be a starting point for further explorations of the interconnections between culture and behaviour.

\section{Final Reflections on the Conference}

Looking back, the conference seemed more multidisciplinary than interdisciplinary in nature, a fact that was acknowledged by speakers and participants. It seems that more time and discussions will be needed to synthesise approaches and jointly develop concepts. However, this is an important first step to spark a longer-lasting discussion between fields. A special issue on norms, culture and behaviour is planned as an outcome from this conference and presents a further step towards finding truly interdisciplinary approaches to address this issue. 


\section{Where is more work needed? And where do we go from here?}

Each of the speakers had their own recommendations for future research and for the future of academia with regards to multi- and interdisciplinary research. Fischer recommended stronger experiments for researching behaviour across cultures. He also challenged the participants to attempt to unpack culture further. Holliday also identified the lack of an established language for talking about culture as a block on current research. Angouri encouraged the participants to look at the structure of academia, which may not be ready for completely interdisciplinary approaches. One example for this would be the viva, which encourages research students to position themselves within one field over another in the choice of examiners. Klaus highlighted that there was not any one best approach but that different research questions demanded different approaches, which may or may not best be interdisciplinary. From our point of view more conceptual work needs to be done around the distinctions between culture and behaviour, as they do not always seem to be clearly elaborated on. We see some pragmatic challenges in terms of conducting multi- and interdisciplinary research of the type recommended by the speakers. It may not be practical to expect individual researchers to have the time and resources to conduct multi-method research. Collaboration between disciplines may be a way of overcoming these challenges; however, it requires interdisciplinary events in order for researchers to make connections, and institutional support for the resulting research to be successfully undertaken.

\section{Acknowledgements}

The authors of this article would like to thank the Warwick ESRC Doctoral Training Centre for funding this event, as well as Professor Helen Spencer-Oatey, Dr Daniel Dauber and Dr Jo Angouri for their help in the organisation and conceptualisation of the event. We would also like to extend our gratitude to the speakers and participants who made the event so successful, and the Centre for Applied Linguistics and the Working and Communicating Across Cultures (WACC) research group for their support. 


\section{References}

Fischer, R (2009), 'Where is Culture in cross cultural research? An outline of the multilevel research process for measuring culture as a shared meaning system', International Journal of Cross Cultural Management, 9 (1), 25-49

Geertz, C. (1973), The Interpretation of Cultures, New York: Basic Books Hofstede, G. (2001), Culture's Consequences: Comparing Values, Behaviors, Institutions and Organizations across Nations, Thousand Oaks, CA: SAGE

Holliday, A. (2016 in press), 'PhD students, Interculturality, Reflexivity, Community and Internationalisation', Journal of Multilingual and Multicultural Development

House, R.J., P.J. Hanges, M. Javidan, P.W. Dorfman, C. and V. Gupta (eds) (2004), Culture, leadership, and organizations: The GLOBE study of 62 societies, Thousand Oaks: Sage Publications

Sapir, E (1921), Language: An Introduction to the Study of Speech, New York: Hartcourt, Brace and World

Trompenaars, F. and C. Hampden-Turner (1998), Riding the Waves of Culture, New York: McGraw-Hill

\section{To cite this article:}

Debray, C., Greenaway, T., \& Kim, K. (2016). Exploring the Interconnections between Culture and Behaviour: an Interdisciplinary Conference at the University of Warwick. Exchanges: The Warwick Research Journal, 3(2), 262272. Retrieved from:

http://exchanges.warwick.ac.uk/index.php/exchanges/article/view/101 